\title{
Energy and comfort benefits of a cool roof application in a non-residential building belonging to Roma Tre University
}

\author{
E. Carnielo ${ }^{1, *}$, A. Fanchiotti ${ }^{1}$, M. Zinzi ${ }^{2}$ \\ ${ }^{1}$ Roma Tre University, Rome, Italy \\ ${ }^{2}$ ENEA Research Center, Rome, Italy \\ *Corresponding author. Tel: +39 3493678683, Fax: +39 065593732, E-mail: emiliano.carnielo@gmail.com
}

\begin{abstract}
The Mediterranean architecture was characterized by passive solutions able to ensure thermal comfort conditions in the built environment during the hot season. This cultural heritage is almost disappeared, delegating the comfort conditions to artificial systems. One of the above mentioned passive solutions concerns the use of light colors to redirect most of the incident solar radiation. Cool roofs are a mix of these old concepts and modern technologies. The paper reports the results of a cool roof application in a senior recreation center, belonging to Roma Tre University. The cool roof was applied on a part of the whole surface of the roof in order to assess the difference in thermal conditions obtained with this solution compared to the original case. The experiment was carried out in two phases. During the first phase the building was monitored with sensors of temperature, humidity and solar radiation. The second phase concerned the creation of a building model inputted in a dynamic simulation tool used to evaluate the building performances due to this cooling technique. This study demonstrate the positive impact of the technology in terms of cooling and total energy savings as well as on the indoor thermal conditions in Mediterranean buildings.
\end{abstract}

Keywords: Cool roof, Passive cooling, Reflectance, Emissivity

\section{Introduction}

Global warming is a planetary problem monitored depending on latitude and economic development but with completely different intensity and consequences in relation to these two influences. The Mediterranean area is particularly vulnerable, with a predicted temperatures increase of $2{ }^{\circ} \mathrm{C}$ by 2030, and with alarming expectations by 2100 (IPCC, 2007). This is the scenario in which lies the need for new energy-saving techniques for conserving nature and preserving public health in every area of development. This problem is present even in the civil sector and in particular it is mainly due to two factors: The emergence of the urban heat island phenomenon and the continuing growth in electricity consumption for summer air conditioning of buildings, not only for the tertiary but recently also for the residential sector. One of the techniques used to limit the dangers associated with the temperature rise is the passive cooling of buildings that includes the use of cool roof [1].

Cool materials are those materials that do not rise significantly their surface temperature under solar radiation. They are characterized by a high solar reflectance (high ability to reflect solar radiation incident on the material) and thermal emissivity (high ability to radiate heat in the infrared wavelengths). The high reflectivity is due to pigments characterized by a high reflectance in the infrared portion of the solar spectrum, maintaining the typical profile in the visible spectrum. This means that the material does not warm up significantly during daylight hours. High emissivity allows the material to stay cool during the night, radiating towards the sky the heat absorbed during the day. The employ of these materials is very useful for the construction of roofs, being the most used building materials characterized by high solar absorption (and therefore low reflectance). The application of cool roof technology can produce a surface temperature profile lower than a normal coating. This leads to a reduction of heat flow entering the building, contributing to an effective reduction in the average indoor air temperature or a reduction in consumption for cooling [2]. The large use of materials with these characteristics in an urban area also leads to indirect energy savings related to the high solar reflectance which reduces the temperature of the agglomerate of buildings. The decrease 
of temperature induces a better energy balance in the areas involved and facilitates the mitigation of urban heat island effect [3]. Cool roofs are not necessarily realized with paints, in fact different technological solutions exist for the reflective cool coatings: Membranes, sheaths, asphalt, bitumen, paving bricks [4]. The most common construction materials for roofs have a reflectance between 20 and 30\%, with a significant solar load for the rooms directly under the ceiling. Fig. 1 shows the trend of the reflectance as a function of wavelength for some cool materials and common materials.
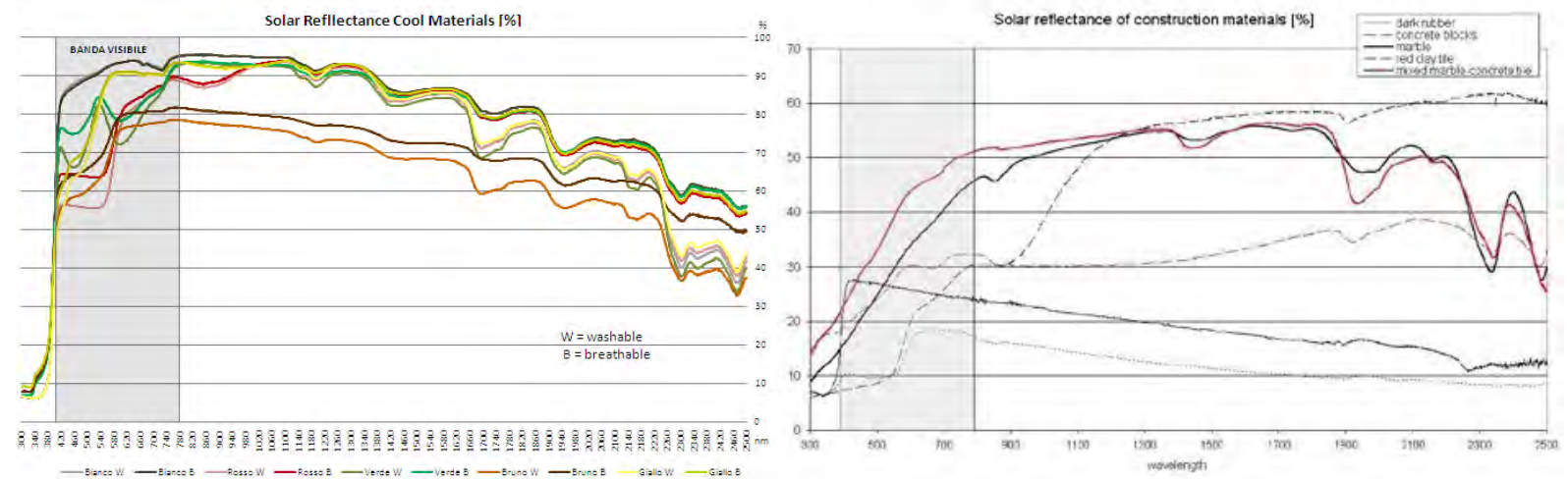

Fig. 1. Solar Reflectance [\%] for Cool Materials and Typical Materials

The thermal emissivity of building materials is generally between 0.8 and 0.9 . Only the metals have lower values of emissivity and this limits the radiant power towards the sky during night. For this reason, metal cool roofs shall be efficient only if they have extremely high values of solar reflectance (greater than 0.75-0.8). An unexplored aspect is related to the maintenance of the initial properties of the products. A rapid decrease in efficiency of material would render useless the economic investment.

\section{Case Study: Social and cultural center "Vasca Navale"}

The building examined in this work is situated in Rome close to San Paolo district. It is located on a plot belonging to Roma Tre University, and recently has been used as a senior recreation center.

The choice fell on this building because it has standard features for study to which it was submitted. Indeed it is an excellent test bench to verify the performances of a high reflectance roof. This is due to the extended horizontal surfaces that capture solar radiation. The plan of the structure extends mainly in length and has an area of $275 \mathrm{~m}^{2}$. The layout of the rooms is very simple: There are five rooms arranged in a row and they are all characterized by a rectangular plan. The orientation of the longer sides is South-North. The entire structure has a low insulation level characterized by transmittance values significantly higher than those established by Italian reference standard for the climate zone of Rome [5]. The Table 1 shows the layers of vertical walls, ceiling, floor, internal walls, their thickness and transmittance.

Table 1. Wall Layers

\begin{tabular}{lccccc}
\hline & Ext.Wall & Ceiling & Floor & Int.Wall & WindowSingleGlazed \\
\hline Thickness $[\mathrm{m}]$ & 0.350 & 0.310 & 0.475 & 0.210 & - \\
Transmitt. $\left[\mathrm{W} / \mathrm{m}^{2} \mathrm{~K}\right]$ & 1.23 & 0.96 & 0.91 & 1.6 & 2.8 \\
\hline
\end{tabular}

The windows are single glazed (Table 1 ) equipped with a dark gray aluminum frame for which it was suggested an absorbance of solar radiation of $85 \%$. The frame area occupies about $30 \%$ of the total area of a window. 


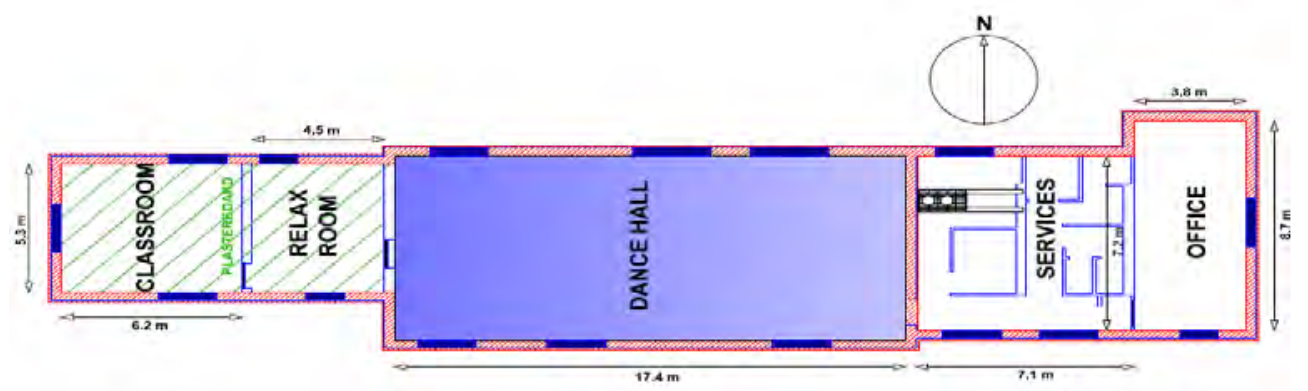

Fig. 2. Plan of Recreation Center

Inside, the ceiling has a height of 3.8 meters except in the classroom and in the relax room (Fig. 2) where there is a suspended ceiling made of plasterboard to 3.1 meters above the ground. In these two rooms the phenomena of heat exchange with the outdoor take on different characteristics compared to the other three rooms, due to the presence of an air gap in the ceiling of 70 centimeters. In blue (Fig. 2) it is shown a portion of the roof of $133 \mathrm{~m}^{2}$ on which a cool roof was applied, corresponding to the "Dance Hall". The material used for the roof is a white mineral membrane based on milk and vinegar of Ecobios Laboratories. The original roof is a bituminous sheath. The superficial layer is made of slate. Samples of the two types of materials were analyzed with a double beam spectrophotometer from which the trend of the reflectance was obtained as a function of the wavelength of the incident beam between 300 and 2500 nanometers. The bituminous slated sheath does not have a uniform color. For this reason three tests were carried out in three different portions where the beam generated by the spectrophotometer affects the corresponding sample. An arithmetic average was carried out to obtain the trend of the reflectance. With the data obtained by the spectrophotometer, it was performed a weighted average of the reflectance values in the range considered (300 $\mathrm{nm}$ $2500 \mathrm{~nm}$ ) according to ISO 90502003 following the energy distribution of the solar spectrum [6]. The integrated reflectance for the slate is $13.7 \%$. It is very low if compared to the one of the mineral membrane Ecobios which reaches a value of $86.4 \%$. The Fig. 3 shows the comparison between the measured reflectance: In blue it is shown the cool material, the other three trends are the tests relating to slate, they have slight differences depending on the point of incidence of the light beam outgoing from the instrument on this surface. Regardless the expected behavior in the wavelength of visible (the membrane is white mineral, slate is dark gray), the cool material presents very interesting values of reflectance in the wavelength of near infrared. Indeed it has a value of more than $95 \%$ in a range that goes from 770 to 1100 nanometers. The reflectance of the slated sheath remains consistently below $20 \%$ throughout the measuring range. Both materials have a thermal emissivity of 0.88 .

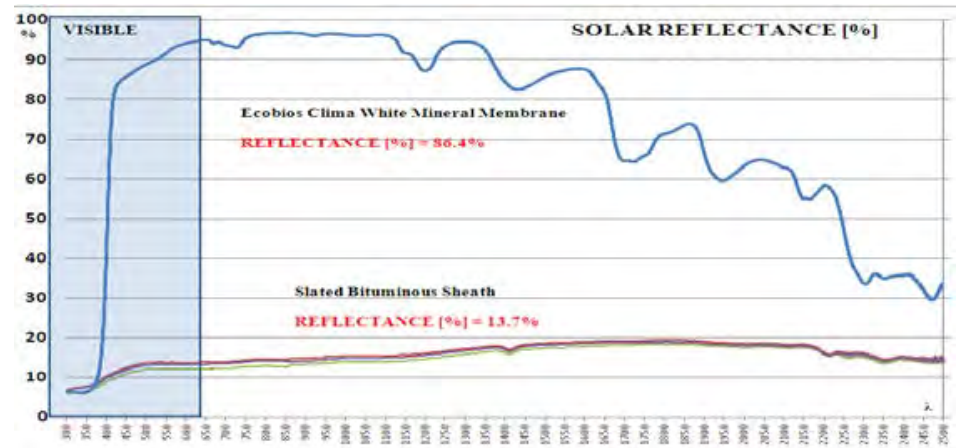

Fig. 3. Solar reflectance [\%] of Ecobios Clima cool membrane and a slated sheath 


\section{Placement of Sensors}

A pyranometer to measure the intensity of solar radiation and a sensor for measuring outdoor temperature and humidity were placed on the roof. In this way it was possible to collect data on the weather during the measurement campaign [7]. This data were also inserted into the TRNSYS processor radiation software to obtain more realistic simulation results. To compare the surface temperatures between the two different roofs, two heat-resistance were placed on the cool roof and two on the slated sheath. In order to monitor the temperature on each side of the roof two other heat-resistance were placed in the inner surfaces of it. Sensors for indoor air temperature and humidity were placed in the "Dance Hall" where the cool roof is applied, in "Services" and in "Office". In this way it was possible to verify the efficiency of a cool roof on the indoor temperature of a room in comparison to the other indoor temperatures. On $12^{\text {th }}$ August, after a routine check on the conditions of the cool roof, a layer of dust and soil was found on its surface probably caused by the presence of a dockyard adjacent to the building in question. This incident has caused the depletion of the surface properties of the cool material, decreasing its efficiency. The TRNSYS simulation software was used to determine the new value of reflectance detected in the points most affected by the problem just mentioned. Indeed, after creating a model of roof to simulate the surface temperature, the reflectance of it was changed to obtain a temperature profile very similar to the one measured by the sensors. By performing the above procedure, the new solar reflectance value found is $68 \%$.

\section{Comparative analysis of measured data}

\subsection{Temperature profiles}

Through the data stored by the surface temperature sensors, it was possible to produce the temperature profiles of the outer and inner surfaces of the roof slab. The profiles of the "Dance Hall" above which was applied the membrane with high reflectance (blue) were compared to the profiles of the area called "Office" characterized by the slated sheath (red). The comparisons, shown in Fig. 4, refers to two days of August. The temperature of the surface of the reflective membrane is significantly lower than the one of the slated sheath. The maximum of the difference between the two outer surfaces is in the middle of the day at the peak of solar radiation when cool roof has the highest efficiency.
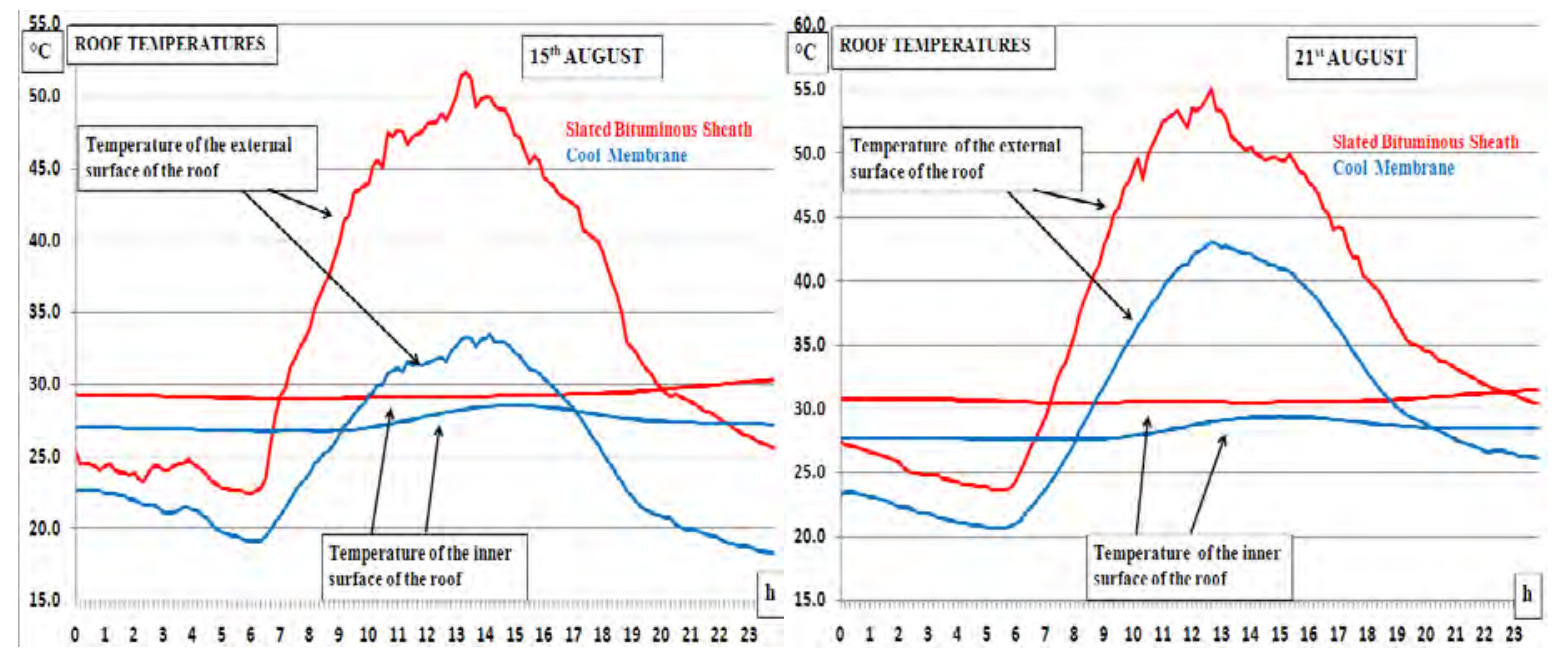

Fig. 4. Surface temperature profiles of the roof (Cool Membrane and slated roof)

The difference in temperature is above $20^{\circ} \mathrm{C}$. A lower surface temperature will decrease the heat flow through the roof changing the indoor temperature. 


\subsection{Comparison of internal temperatures}

It was not possible to monitor simultaneously the difference in indoor air temperature due to the cool membrane and the original slate mantle in the same thermal zone. For this reason two periods of two days were chosen, corresponding to the beginning of two heat waves in July and August whit almost identical trends of solar radiation and outside temperature. In the first of these two periods the cool roof had not yet been applied to the area of interest. In this way it was possible to compare the values of indoor air temperature in a room equipped with and without a cool roof.

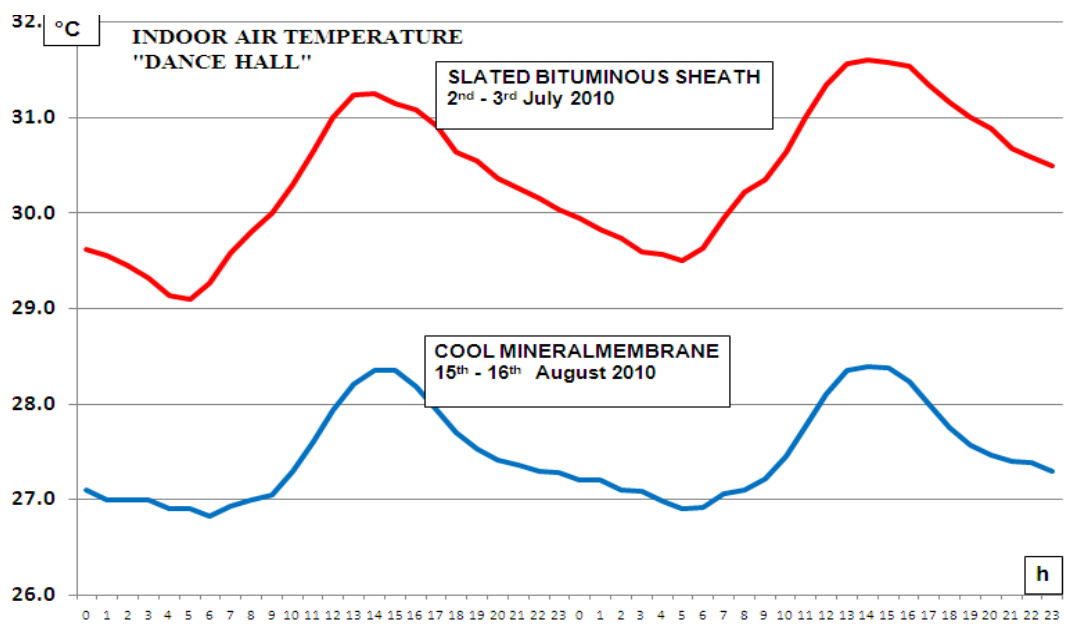

Fig. 5. Indoor air temperature of the "Dance hall"

In the Fig. 5 above, the trend in blue, typical of a cool roof, denotes the positive effect of this technology of passive cooling by limiting the maximum temperature below $28.5^{\circ} \mathrm{C}$. With the slated sheath the values are higher than $31{ }^{\circ} \mathrm{C}$. It is important to remember that the performance measured are relative to a cool roof not at its maximum efficiency, but with limited performance due to dust and soil deposited on it.

\section{Simulations Results}

The model included in the simulation software TRNSYS was calibrated to the measured indoor temperature profile and to the external surface temperature of the roof. To achieve optimal calibration, the parameters of air infiltration and the values of internal and external shading of non-opaque surfaces were modified obtaining a maximum deviation between the real temperatures and those obtained with the simulator under three tenths of a degree. The first session of simulations is aimed at obtaining a comparison of results for the internal operative temperature with no cooling systems. The second part concerns the evaluation of air conditioning loads. Both sessions were conducted considering three reflectance values of the roof slab.

Three models were created, each one with a different value of insulation:

1. Real values of insulation of the building;

2. Real values of insulation of the building except the transmittance of the roof according to Italian standard reference;

3. Insulation according to Italian standard reference Zone $D$ (vertical wall $=0.36 \mathrm{~W} / \mathrm{m}^{2} \mathrm{~K}$, ceiling $=0.32 \mathrm{~W} / \mathrm{m}^{2} \mathrm{~K}$, floor $=0.36 \mathrm{~W} / \mathrm{m}^{2} \mathrm{~K}$, window $=1.9 \mathrm{~W} / \mathrm{m}^{2} \mathrm{~K}$, window with frame including $2.4 \mathrm{~W} / \mathrm{m}^{2} \mathrm{~K}$ ) for the entire building. 


\subsection{Operative Temperatures}

The operative temperature of a zone is the temperature which takes into account both the internal air temperature and the average temperature of the inner surfaces of the structure. From the simulations results was extracted the total number of hours in which the operative temperature of the "Dance Hall" exceeds some chosen values in the period from $17^{\text {th }}$ June to $1^{\text {st }}$ September. The values of solar reflectance used are: $16 \%$ to simulate the original coating, $86 \%$ for the mineral membrane and $68 \%$ to simulate mineral membrane with performances compromised by dust and soil. The following are histograms for the three chosen levels of insulation.

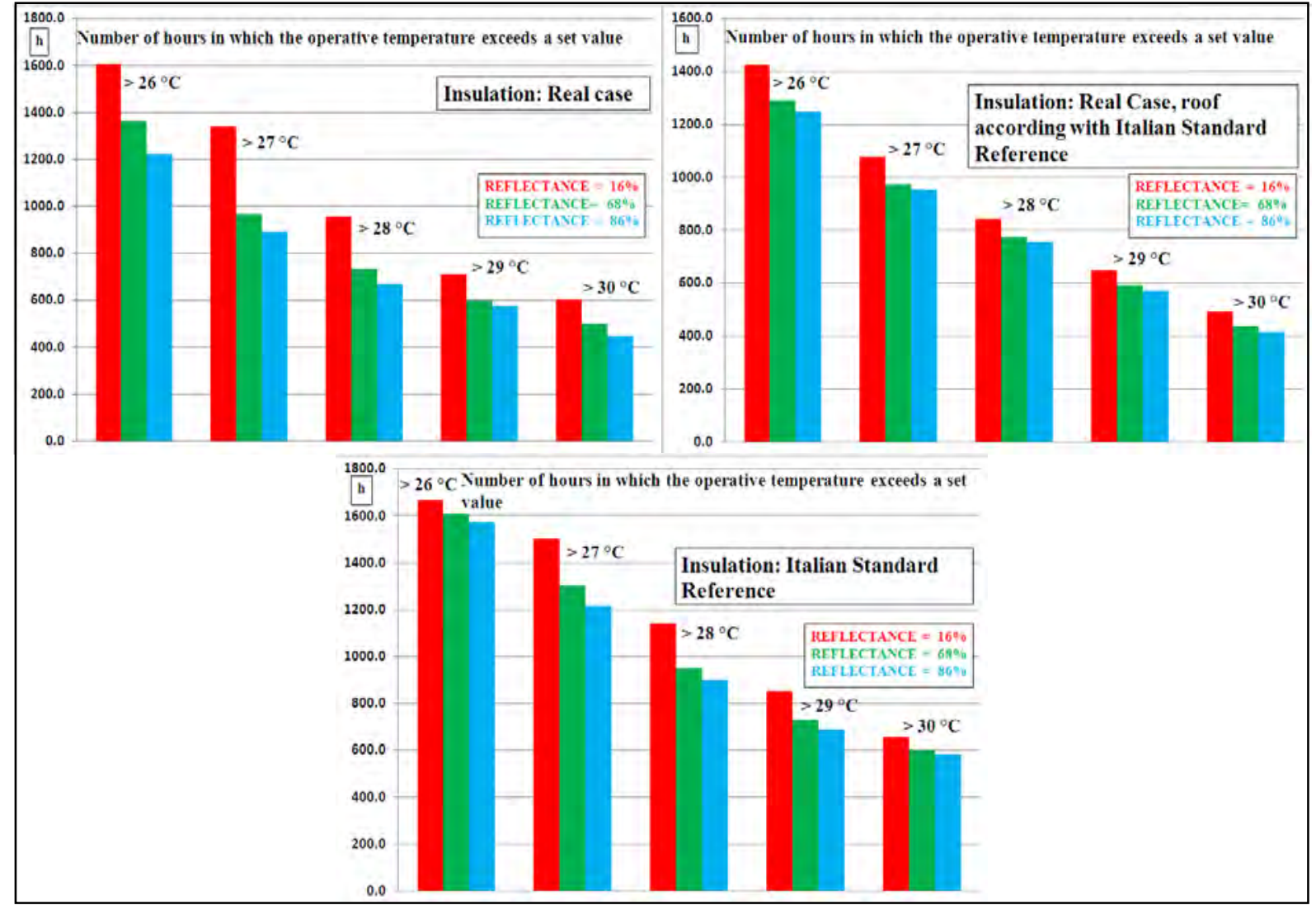

Fig. 6. Operative Temperature, three insulation levels

The use of a high reflectance material is a contributory factor to increase the number of hours in which there are thermal comfort conditions. On the other hand, increasing insulation level, the number of hours in which the temperature is greater than a specific value tends to increase. Indeed, being equal the reflectance, the configuration with insulation according to Italian standard reference has internal temperatures higher than the ones registered in the building with the real level of insulation. This phenomenon occurs in the climatic zone of middle Mediterranean in buildings characterized by high solar gains through non-opaque surfaces. The significant solar gains through windows increase the indoor air temperature. The value of the latter become very similar to the outdoor temperature during daylight. The low transmittance value determines a small outgoing heat flow which lasts even during the night. The heat is trapped inside, creating a sort of greenhouse effect. In warmer climates the gap between indoor and outdoor temperatures is generally high and the phenomenon described above is less evident. 


\subsection{Air conditioning loads}

The simulations performed on the model equipped with an air conditioning system of unlimited power, conducted during summer ( $17^{\text {th }}$ June $-1^{\text {st }}$ September $)$, are designed to assess the extent of energy savings depending on the reflectance of the roof. The reflectance of the roof of the "Dance Hall" assumes the three values previously used. From the results were extrapolated the net loads for the summer period necessary to maintain the temperature of the zone below the set-point of $26^{\circ} \mathrm{C}$ for the three levels of insulation.

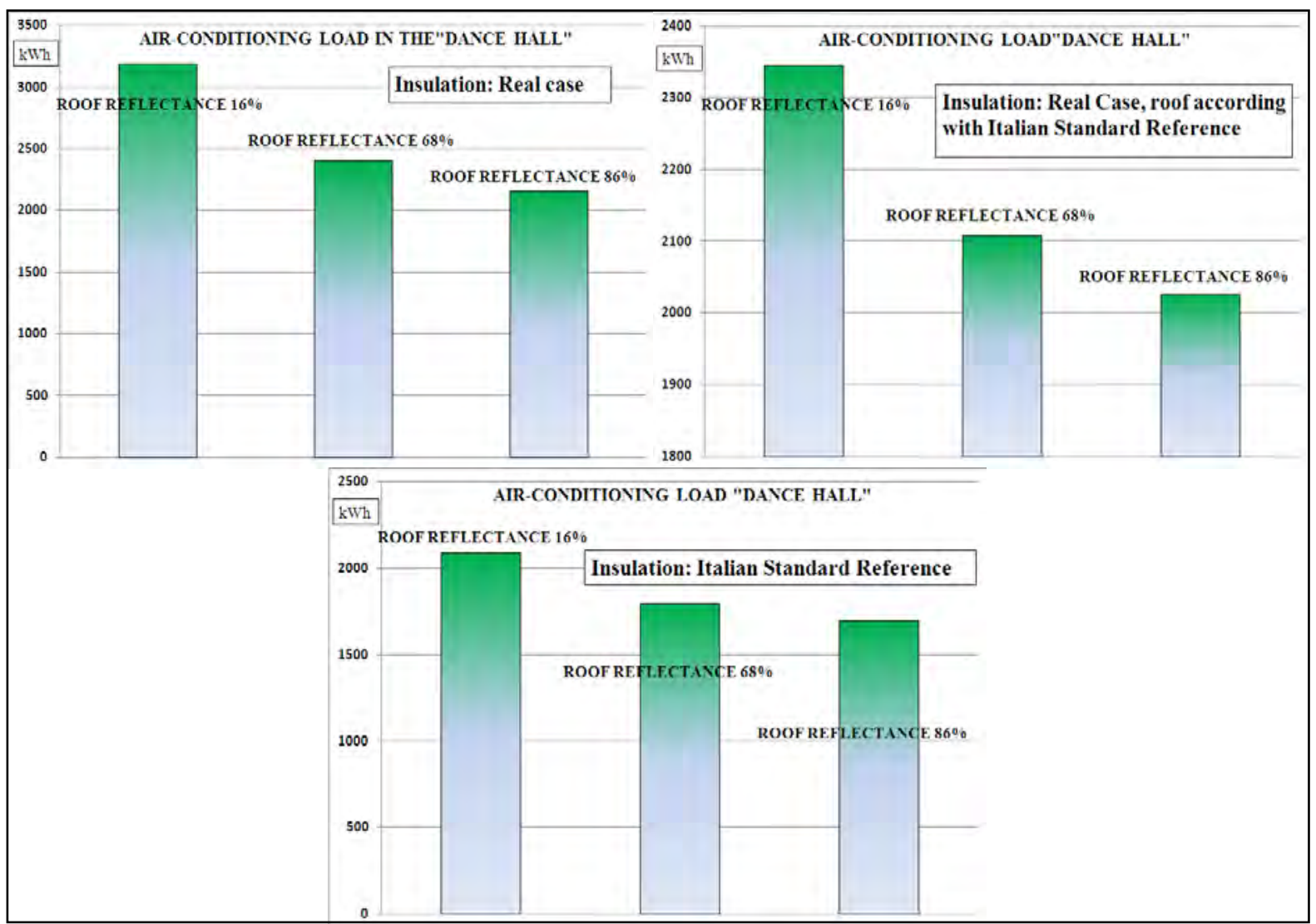

Fig. 7. Air conditioning loads, three insulation levels

Fig. 7 shows a decrease of load proportional to the increasing of reflectance. Again, as in the previous group of simulations, the more insulated building results less sensitive to changes in reflectance. Comparing building with real insulation and roof reflectance of $16 \%$ and building with roof insulation level established by Italian standard reference and roof reflectance $86 \%$, the value of energy used to cool the "Dance Hall", decreases from $3200 \mathrm{kWh}$ to $2050 \mathrm{kWh}$, with a saving of about $9 \mathrm{kWh}$ per square meter. Considering the insulation level in accordance with Italian standard reference for the whole structure of the building, the consumption decreases from $3200 \mathrm{kWh}$ to about $1700 \mathrm{kWh}$ with an energy saving for air conditioning in the area of about $12 \mathrm{kWh}$ per square meter. Considering the entire warm season, including the months of May and September, the savings would be greater, even more if a cool roof were applied over the entire roof surface.

\section{Conclusions}

The application of a cool roof reduces roof surface temperatures, limiting the incoming heat flow from it and, in any case, decreasing the temperature of the indoor environment. The case study examined in this report has demonstrated, through appropriate measurements of temperature, the potential of a cool roof. The Ecobios Clima reflective membrane has proved 
to be an excellent material for this use. The ease of application on any surface is another quality of this product. The area of the building that received the benefits from the application of this membrane is affected by a large number of thermal factors that have tested the capabilities of the cool roof. The large glass surfaces exposed to the South are subjected to heavy solar gains and even if they were shielded from direct sunlight they influenced the indoor temperatures. Adding to this, the poor insulating level and low volume of air circulation make the Dance Hall the more thermally critical zone of the building. The cool roof decreased the indoor air temperatures by $2.5{ }^{\circ} \mathrm{C}$ in average. This is a very interesting result considering the fact that it did not work at its maximum value of reflectance because of external agents described above. It was possible to quantify the extent of energy saving on internal loads, noting in this case as it increases in direct proportion to the level of reflectance. Benefits relating to this passive technique of cooling are obtained even only increasing both levels of reflectance and insulation of a roof. From the observations made in this report, it is possible to note that the employ of a cool roof on existing buildings and on new buildings under construction with expected high insulation levels offers significant advantages in both cases.

\section{References}

[1] M. Zinzi for Earthscan/Aber, Advances in building energy research, vol.4, Cool materials and cool roofs: Potentialities in Mediterranean buildings, Earthscan, 2010, pp. 1 - 6.

[2] M. Zinzi for Earthscan/Aber, Advances in building energy research, vol.4, Cool materials and cool roofs: Potentialities in Mediterranean buildings, Earthscan, 2010, pp. 6-11.

[3] A. Christen, R. Vogt, Energy and radiation balance of a central European city, International Journal of Climatology 24, (2004), pp. 1395 - 1421.

[4] Cool Roofs - EU, Database of cool materials, www.coolroofs-eu.eu.

[5] DLgs 192 August 19 $9^{\text {th }}$, Implementation of directive 2002/91/CE on energy efficiency in buildings (Italian standard reference), 2005, pp 16 - 17.

[6] ISO 9050, UV, visible and energetic characteristics of materials, 2003.

[7] A. Fanchiotti, E. Carnielo, (Data collection), Impatto di tecnologie Cool Roof sulle prestazioni energetiche degli edifici. Caso Studio (Cool Roof technology impact on energetic performances of buildings. Case Study), ENEA, 2010, pp. 27 - 58. 